\title{
Effect of Preheating Temperature and Cooling Rate on the Microstructure Development of Welded Pearlitic Rail Steel
}

\author{
Heshmat Aglan and Tanzilur Rahman \\ Tuskegee University, Tuskegee, Alabama, United States
}

The heat affected zone (HAZ) formed due to vigorous heat treatment and recrystallization during welding is the most critical zone. Failure at the HAZ has been reported to be as a result of change in microstructure and reduction of mechanical properties [1]. Variation in preheating temperature and cooling rate has a significant effect on microstructure and mechanical properties of the HAZ of welded pearlitic rail steel and formation of martensite at higher cooling rates has been reported [2]. Slow cooling rates increased both the grain size and interlamellar spacing of the pearlite colony in the HAZ of welded rail [3]. Narrow interlamellar spacing resulted in higher hardness as more of the cementite phase was present there. However, toughness depends only on grain size, with a smaller grain size producing higher toughness [4]. For these reasons, retention of the pearlitic structure in the HAZ after gas metal arc weld (GMAW) finishing is highly desirable and understanding the effect of cooling rate on microstructure needs attention.

Evaluating the microstructure of HAZ of GMAW pearlitic rail steel through controlled cooling is the prime focus of this research. Multipass GMAW has been performed on one sample without preheating, two $300{ }^{\circ} \mathrm{C}$ preheated samples, and one $500^{\circ} \mathrm{C}$ preheated sample to fill the slot of the rail head with Postalloy 2892-SPL hardfacing filler wire. A continuous cooling transformation (CCT) diagram for the working rail steel composition was obtained using JMatPro V11 software. The cooling rate was controlled using insulating materials. One $300{ }^{\circ} \mathrm{C}$ preheated sample was cooled at the rate of $8{ }^{\circ} \mathrm{C} / \mathrm{s}$ and another 300 ${ }^{\circ} \mathrm{C}$ preheated sample was cooled at the rate of $2{ }^{\circ} \mathrm{C} / \mathrm{s}$. The sample without preheating was cooled in open air and the $500^{\circ} \mathrm{C}$ preheated sample was cooled at the rate of $2{ }^{\circ} \mathrm{C} / \mathrm{s}$. The controlled cooling rate was measured using an infrared thermocouple. Samples were cut for microstructural analysis and were polished and etched with $2 \%$ nital. Optical micrographs of the etched samples were evaluated using the Olympus GX51 inverted metallurgical microscope.

Figure 1(a) represents the micrographs taken from the fast cooled HAZ, while the slower cooled HAZ micrographs are shown in Figure 1(b). Figure 1(a) exhibits an appearance of bainite in the microstructure. Due to the faster cooling rate, cementite (orthorhombic, $\mathrm{Fe}_{3} \mathrm{C}$ ) layer could not be formed there because the carbon was still dissolved in the austenite. The microstructure of the slower cooled HAZ in Figure 2(a) consists of fine grained pearlite, which is highly desired.

Figure 2(a) represents the micrographs taken from the no preheated sample, while the $500^{\circ} \mathrm{C}$ preheated sample micrographs are shown in Figure 2(b). Figure 2(a) exhibits an explicit appearance of martensite in the microstructure. The microstructure of the $500^{\circ} \mathrm{C}$ preheated sample $\mathrm{HAZ}$ with slow cooling in Figure 2(b) consists of coarse grained pearlite. The grains of pearlite in $500^{\circ} \mathrm{C}$ preheated sample in Figure 2(b) are a larger than those of the $300^{\circ} \mathrm{C}$ preheated sample in Figure 1(b).

The cooling rate obtained from JMatPro to attain pearlitic microstructure in the heat affected zone of a pearlitic rail steel after GMAW has been achieved experimentally. Since a higher cooling rate can form bainite, even martensite, in the $\mathrm{HAZ}, 2{ }^{\circ} \mathrm{C} / \mathrm{s}$ is the recommended cooling rate for GMAW of pearlitic rail steel to get desired pearlitic structure in the $\mathrm{HAZ}$ with $300^{\circ} \mathrm{C}$ preheating. 

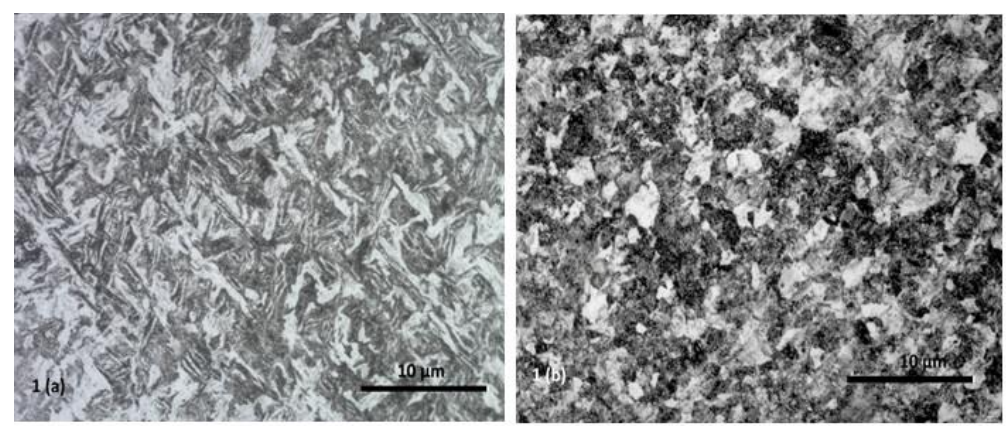

Figure 1. Optical micrographs of (a) fast cooled HAZ and (b) slow cooled $\mathrm{HAZ}$ with $300^{\circ} \mathrm{C}$ preheat
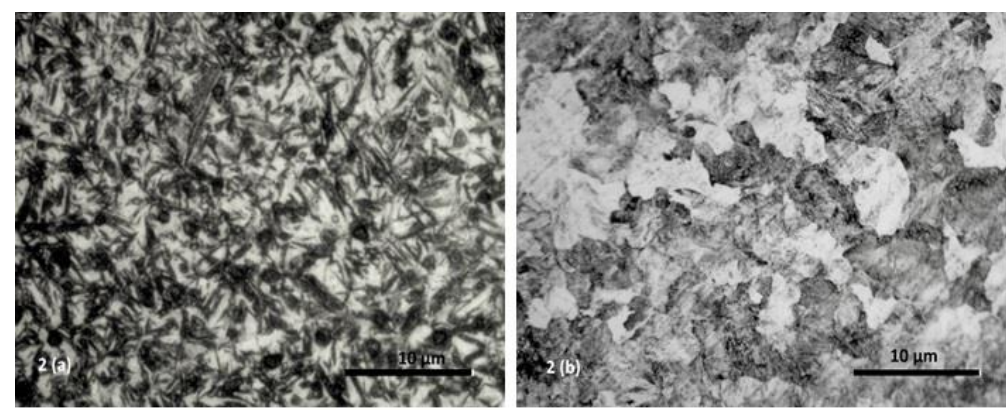

Figure 2. Optical micrographs of (a) fast cooled HAZ with no preheat and (b) slow cooled HAZ with $500^{\circ} \mathrm{C}$ preheat

\section{References}

[1] H.-K. Jun, J.-W. Seo, I.-S. Jeon, S.-H. Lee, and Y.-S. Chang, "Fracture and fatigue crack growth analyses on a weld-repaired railway rail," Engineering Failure Analysis, vol. 59, pp. 478-492, Jan. 2016. [2] Georgy Grigorenko, Valery Kostin, Victor Zhukov, and Tetiana Zuber, "Peculiarities of Structural Transformations in HAZ Metal of Rail Steel M76 Joint Produced by Flash-Butt Welding," JPSA, vol. 6, no. 5, May 2016.

[3] R. R. Porcaro, G. L. Faria, L. B. Godefroid, G. R. Apolonio, L. C. Cândido, and E. S. Pinto, "Microstructure and mechanical properties of a flash butt welded pearlitic rail," Journal of Materials Processing Technology, vol. 270, pp. 20-27, Aug. 2019.

[4] A. R. Khan, S. Yu, H. Wang, and Y. Jiang, "Effect of Cooling Rate on Microstructure and Mechanical Properties in the CGHAZ of Electroslag Welded Pearlitic Rail Steel," Metals, vol. 9, no. 7, p. 742, Jul. 2019. 